HASIL CEK_The Formation of Local Catalyst From Zeolite, Characterization and

Performance in the Reaction by Zahrul Mufrodi 60010305

Submission date: 01-Nov-2021 10:17AM (UTC+0700)

Submission ID: 1689552543

File name: om_Zeolite,_Characterization_and_Performance_in_the_Reaction.pdf (1.26M)

Word count: 2244

Character count: 11997 


\title{
The Formation of Local Catalyst From Zeolite, Characterization and Performance in the Reaction
}

\author{
Zahrul Mufrodi, Erna Astuti ${ }^{1, a}$ and Gita Indah Budiarti ${ }^{1}$ \\ ${ }^{1}$ Department of Chemical Engineering, Universitas Ahmad Dahlan, Yogyakarta, Indonesia \\ aerna.astuti@che.uad.ac.id
}

Keywords: Catalyst, zeolite, activity, density, SEM and XRD

\begin{abstract}
The existance of catalyst in a chemical reaction is very important. This catalyst can accelerate the chemical reaction. Currently there are local catalyst with the performance as good as commercial catalyst. One of 5 those catalyst is zeolite. This paper determines the study of characterization of zeolite using Scanning Electron Microscope (SEM) and X-ray Diffraction (XRD), and explains the perfomance of zeolite in the synthesis of triacetin. Catalyst from zeolite was made 12 mixing with $\mathrm{H}_{2} \mathrm{SO}_{4}$ in various concentrations, neutralization and drying. From morfology analysis by using Scanning Electron Microscope (SEM), density and X-Ray Diffraction (XRD) obtain that mixing with $\mathrm{H}_{2} \mathrm{SO}_{4}$ of $0.5 \mathrm{M}$ is better than the others. From the study of catalyst synthesis from natural zeolite it can be concluded that natural zeolite before activation has fragile structure meanwhile after being activated it was formed crystal structure. The best zeolite crystal phase was obtained from zeolite activated by using $0,5 \mathrm{M} \mathrm{H}_{2} \mathrm{SO}_{4}$ with glycerol conversion of $94.45 \%$ and triacetin selectivity of $4.01 \%$.
\end{abstract}

\section{Introduction}

Catalyst has important role in accelerating chemical reaction. Currently, there are many relatively high price catalysts. Solid catalysts are widely used for liquid or gas reactant. Reaction with gas or liquid reactant and solid catalyst is a good option because the product is easily separated from the catalyst. To fulfill the catalyst demand it is necessary to develop alternative catalyst with relatively cheaper price. Natural zeolite is a solution which can be utilized as catalyst, besides its abundant availability it is also relatively cheap compare to commercial catalysts.

Zeolite is a hydrated alumina silicate crystalline with three dimensional open structure which can be prepared to increase its activity [1]. Zeolite has function as catalyst due to its surface characteristic. In this study it is expected that this research make zeolite catalyst and used it for heterogeneous reaction.

Catalyst. Catalyst is a substance that increases the rate of a chemical reaction without itself undergoing any permanent chemical change and does not affect equilibrium of reaction. In industry catalyst has been widely $\sqrt{4} \mathrm{ed}$, especially in chemical industry. Based on its phase, catalysts are classified as homogeneous and heterogeneous catalyst. Homogeneous catalyst is a catalyst which has the same phase as the reactant. Heterogeneous catalyst is a catalyst which has different phase from the reactant. Homogenous catalyst works through interaction of reactant particles to transitional state. Furthermore transitional state merge with the other reactants to form product, after the product is formed the catalyst regenerate into pseudo substance. Heterogeneous catalyst is commonly in a form of solid which can be used for gas or liquid reactant and the reaction occur on catalyst surface. The materials used as heterogeneous catalyst is a precious metal such as platinum Rhodium and Palladium. However because it's limited amount and high prices thus it limit the usage [2]. Therefore study to produce catalyst from relatively cheap raw natural material is necessary without neglecting the quality of the catalyst.

The performance of catalyst to increase the reaction rate is affected by various factors. The factors affecting catalyst performance are physical and chemical properties of catalyst; operating condition such as temperature, pressure, flow rate, contact time; feed type; the type of supporting solid usen The catalyst prepared with different method will give different activity and selectivity. The ability of 
catalyst in accelerating the reaction rate is affected by several factors. The factors affecting the catalyst performance are physical and chemical properties; operating condition such as temperature, pressure, flow rate, contact time; feed type; and the type of supporting solid used. The catalyst prepared with different method will give different activity and selectivity [3].

Zeolite as Catalyst. Zeolite is silica-alumina crystal material which has three dimensional polymer arrangement consists of tetrahedral unit $\mathrm{SiO}_{4}$ and $\mathrm{AlO}_{4}{ }^{-}$, which merge through oxygen sharing. Zeolite structure can be seen on Fig. 1. Based on its solid structure which has pores and hollow and also has high thermal stability, zeolite-like material can be functioning as catalyst metal support or adsorbent [4].

Zeolite can be used direct waste absorbent. However, to increase the zeolite absorbance ability, activation is necessarily to be conducted. Activation process can be conducted through acidification [5]. Zeolite also has micro porous structure so that it can provide wide spaces for reaction to occur in higher pressure. High $\mathrm{Si} / \mathrm{Al}$ ratio in zeolite make it hydrophobic-organophilic which will promote reactant diffusion process. Zeolite molecular dimension also makes zeolite selective toward reactant, product and transitional condition.

Triacetin. Glycerol can be made of triacetin and trinitroglycerin [6-10]. Triacetin as bio additive can be synthesized by using glycerol and acetic acid [11]. Various solid and liquid catalyst can be used in this reaction to increase the rate of reaction. Solid catalysts which has been used were Fe-Sn-Ti $\left(\mathrm{SO}_{4}{ }^{2-}\right)$ [12], Zr-Natural Zeolite [13], and silica alumina [14], sulfuric acid [15-17]. This research used zeolite as heterogeneous catalyst ir 5 he formation of triacetin. So this paper determines the study of characterization of zeolite using Scanning Electron Microscope (SEM) and X-ray Diffraction (XRD), and explains the perfomance of zeolite in the synthesis of triacetin.

\section{Methods}

Catalyst was made by reduce the size up to 200 mesh, then mixed with $\mathrm{H}_{2} \mathrm{SO}_{4}$ solution for 4 hours in three neck flask equipped with condensor in the temperature of $90^{\circ} \mathrm{C}$. It was then separated by using filter. The solid was neutralized with distilated water and dried by using oven. It was then decomposed by adding $\mathrm{NaOH}$, stirred for 30 minutes anto washed in order to make neutral. The result which will be analyzed to find out surf 10 morfology using Scanning Electron Microscope (SEM), and to know crystalline structure using X-ray Diffraction (XRD). The density of catalyst before and after activation was also $8 \mathrm{e}$ e measured. The characteristic of activated zeolit calatyst was used for triacetin formation from glycerol and acetic acid. The analysis of triacetin was conducted by using Gas chromatography-mass spectrometry.

\section{Result and Discussion}

Characteristic results of zeolites were analyzed using scanning Electron Microscope (SEM), X-Ray Diffraction (XRD) and density analysis.

Scanning Electron Microscope (SEM) Analysis. The result of morphology of catalyst surface before and after activation is shown on Fig. 1 as follow.

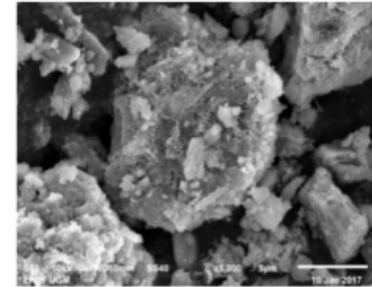

A

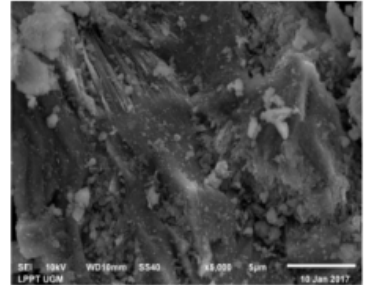

B

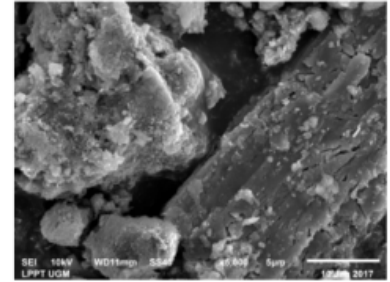

C

Fig. 1. SEM Analysis on a. Natural Zeolite without activation, b. Natural Zeolite activated with $0,5 \mathrm{M}$ $\mathrm{H}_{2} \mathrm{SO}_{4}$, c. Natural Zeolite activated with $1 \mathrm{M} \mathrm{H}_{2} \mathrm{SO}_{4}$ 
The result of zeolite identification by using Scanning Electron Microscope (SEM) is shown on Fig. 1 with zeolite morphology in a form of fragile porous crystal. The activated zeolite was harder and denser, as shown on Fig. 1.b and 1.c. comparatively activated zeolite with $0.5 \mathrm{M} \mathrm{H}_{2} \mathrm{SO}_{4}$ is stronger and has more pores than activated zeolite by using $1 \mathrm{M} \mathrm{H}_{2} \mathrm{SO}_{4}$

X-Ray Diffraction (XRD) Analysis. The result of X-ray Diffraction (XRD) Test before and after activation is shown on Fig. 2 as follow.
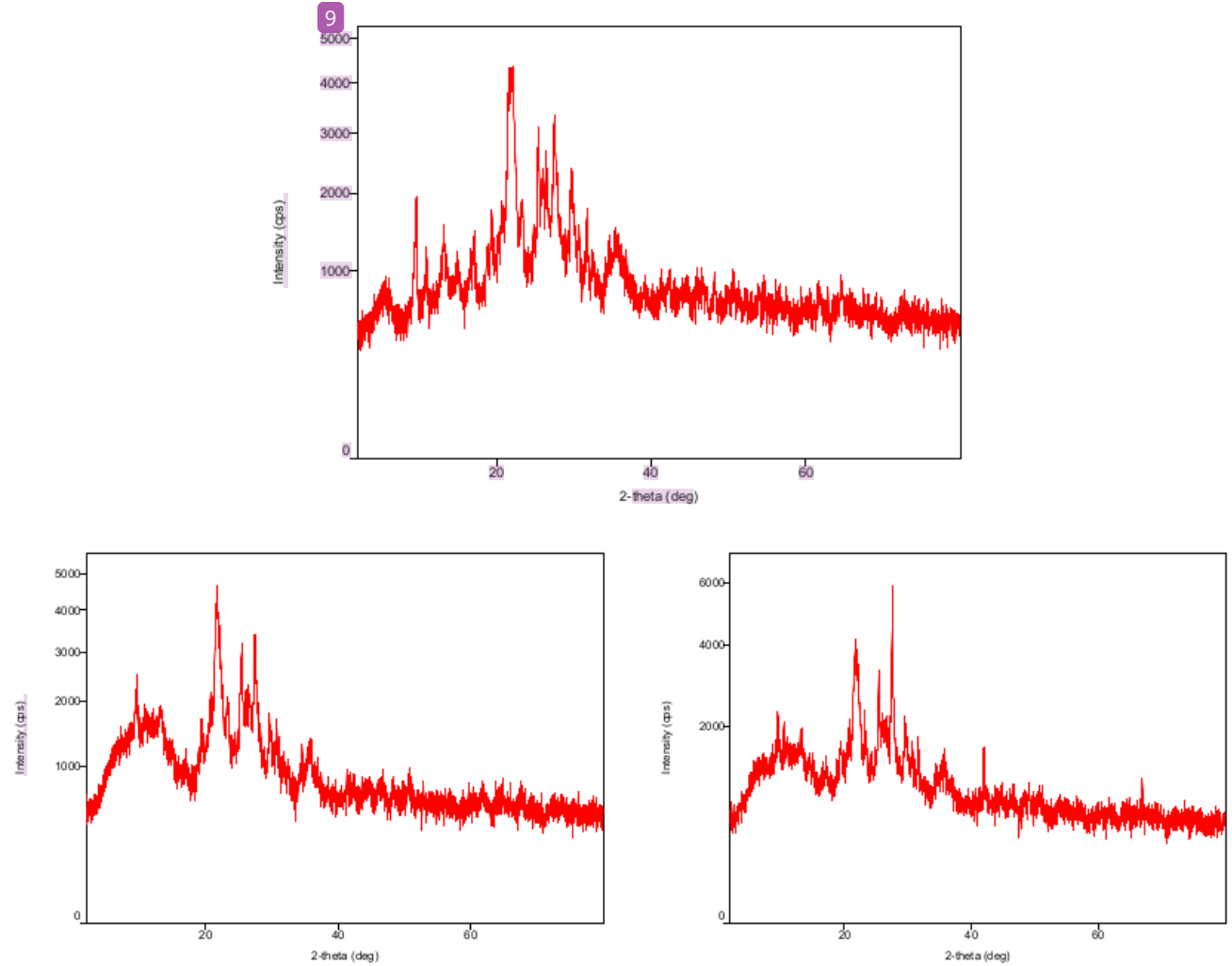

Fig. 2. Zeolite Cristal Structure : a. Natural Zeolite without activation, b. Natural Zeolite activated with $0,5 \mathrm{M} \mathrm{H}_{2} \mathrm{SO}_{4}$, c. Natural Zeolite activated with $1 \mathrm{M} \mathrm{H}_{2} \mathrm{SO}_{4}$

Fig. 2. shows diffractogram as the analysis result by using XRD which shows that amorf phase was more dominant on non-activated zeolite and the crystal phase increased after activation. Amorphous phase can be seen from its peak in of 2 theta area around $0^{\circ}-20^{\circ}$. Meanwhile crystal phase can be seen on Fig. $2 \mathrm{~b}$ and $2 \mathrm{c}$ indicated by the appearance of diffractogram peaks in 2 theta area around $21^{\circ}-31^{\circ}$. Besides it was indicated by a greater number of picks in its crystal structure. From three charts on Fig. 2 both a and $\mathrm{c}$ there is similarity of the existence of amorphous shape in the area around $0^{\circ}-20^{\circ}$ and this figure is not shown on Fig. 2b. Fig. $2 \mathrm{~b}$ shows crystal pikes formed in are around $0^{\circ}-20^{\circ}$.

Density Analysis. For catalyst density test it can be determined from the number of pores formed in which strong crystal structure yet has many pores. The result of density test before and after activation is shown on Table 1.

Table 1. Density of zeolite with and without activation

\begin{tabular}{clc}
\hline No & Activated zeolite using $\mathrm{H}_{2} \mathrm{SO}_{4}$ & Density \\
\hline 1. & Before activation & 20.0 \\
2. & Activated 0.5M & 40.5 \\
3. & Activated 1M & 40.0 \\
\hline
\end{tabular}


Table 1 shows that low density was obtained from zeolite with activation of $0.5 \mathrm{M}$, which mean that pores structure is more prominent in this activation. It acentuated the result of morphology analysis by using SEM and structure analysis by using SEM and crystal analysis by using XRD.

The Role of Catalyst in the Triacetin Formation. Activated zeolite was tested in the triacetin formation with the result as shown in Table 2 as follow.

Table 2. The effect of catalyst on conversion and selectivity, monoacetin, diacetin dan triacetin

\begin{tabular}{lcccc}
\hline \multicolumn{1}{c}{ Zeolite catalyst } & Glycerol & \multicolumn{3}{c}{ selectivity, \% } \\
\cline { 3 - 5 } & conversion, \% & Monoacetin & Diacetin & Triacetin \\
\hline Before activation & 13.61 & 91.73 & 8.27 & - \\
\hline Activated $0,5 \mathrm{M} \mathrm{H}_{2} \mathrm{SO}_{4}$ & 94.45 & 50.32 & 45.67 & 4.01 \\
\hline Activated $1 \mathrm{M} \mathrm{H}_{2} \mathrm{SO}_{4}$ & 70.82 & 60.45 & 39.44 & 0.11 \\
\hline
\end{tabular}

Table 2 exhibit that catalys usage in btriacetin bioaditif synthesizing has good effect compare to without catalyst. The usage of zeolite with the activation using $0.5 \mathrm{M} \mathrm{H}_{2} \mathrm{SO}_{4}$ was better than zeolite withouth activation and activated $1 \mathrm{M} \mathrm{H}_{2} \mathrm{SO}_{4}$ for both glycerol conversion $(94.45 \%)$ and triacetin sel 8 tivity $(4.01 \%)$.

Triacetin can be used to improve the performance of biodiesel. The previous study 3 sed homogeneuous catalyst in syntesis of biodiesel [18,19]. Gnanaprakasam et al. [20] stated that $\mathrm{CaO}$, $\mathrm{CaTiO}_{3}, \quad \mathrm{CaZrO}_{3}, \quad \mathrm{CaO}-\mathrm{CeO}_{2}, \quad \mathrm{CaMnO}_{3}, \quad \mathrm{Ca}_{2} \mathrm{Fe}_{2} \mathrm{O}_{5}, \quad \mathrm{Al}_{2} \mathrm{O}_{3} / \mathrm{KI}, \quad$ ETS-10, zeolite, alumina/silica-supported $\mathrm{K}_{2} \mathrm{CO}_{3}$ can be used as heterogeneous base catalyst in the production of biodiesel from waste coosing oil[20]. This research will be continued with the use of zeolite as local catalyst on the synthesis of biodiesel from waste cooking oil.

\section{Summary}

From the study of catalyst synthesis from natural zeolite it can be concluded that natural zeolite before activation has fragile structure meanwhile after being activated it was formed crystal structure. The best zeolite crystal phase was obtained from zeolite activated by using $0,5 \mathrm{M} \mathrm{H}_{2} \mathrm{SO}_{4}$ with glycerol conversion $94.45 \%$ and triacetin selectivity $4.01 \%$.

\section{Acknowledgements}

The authors would like to thank The Ministry of Research Technology and Higher Education of the Republic of Indonesia who has funded this research grant of The Excellent Applied Research of University Scheme project no. PTUPT-005/SKPP.TT/LPPM UAD/III/2019.

\section{References}

[1] B. Imelik, C. Naccache, G. Coudurier, Y.B. Taarit, and J.C. Vedrine, catalysis by acids and bases, Amsterdam: elsevier

[2] Irawan dan Bagas, Unimus Journal, Vol. 4. No. 1, (2006) p 34.

[3] R.D. Rieke, D. Thakur, B, Roberts, and T. White, .JAOCS, vol. 74, No.4, (1997) p. 333

[4] Sutrisno, B., Z. Mufrodi and A. Hidayat, Chemica, vol.5 (2010) p 4

[5] F. Ribeiro, F. Alvares, Henriques, F. Lemos, J.M. Lopes, and M.F. Ribeiro, Chemical, vol $5,(2010)$ p 245.

[6] E. Astuti, S. Supranto, R. Rochmadi, and A. Prasetya, Eng. J., vol. 18, no. 3 (2014) p 73-82.

[7] E. Astuti, Supranto, Rochmadi, and A. Prasetya, International Journal of Chemical, Molecular, Nuclear, Material and Metallurgical Engineering, Vol. 9, no. 8, (2015) p 947 
[8] E. Astuti, Supranto, Rochmadi, and A. Prasetya, Key Engineering Materials, vol. 718 (2017) p 95-99

[9] E. Astuti, Supranto, Rochmadi, and A. Prasetya, ARPN Journal of Engineering and Applied Science, Vol. 11, no. 8 (2016) p 5203

[10] E. Astuti, Supranto, Rochmadi, A. Prasetya, K. Strom, and B. Andersson, Modern Applied Science, vol. 8, no. 2 (2014) p 78

[11] Z. Mufrodi, A. Budiman, and S. Purwono, Energy Procedia, Vol 145 (2018) p 434

[12] J. Sun, X. Tong, L. Yu, and J. Wan, Catalysis Today, vol. 264, (2016) p 115.

[13] R.B. Cahyono, Z. Mufrodi, A. Hidayat and A. Budiman, ARPN Journal of Engineering and Applied Science, Vol. 11, no 8 (2016) p 5194

[14] A. Aktawan,. and Z. Mufrodi, JBAT, vol. 5 (2), (2016) p 92.

[15] Z. Mufrodi, E. Astuti, A. Aktawan, and S. Purwono, IOP Conference series : Earth and Environmental Science, vol 175 (2018) p 1

[16] Z. Mufrodi, Rochmadi, Sutijan, and A. Budiman, Eng. Journal, vol. 18 (2)(2013) p 30

[17] A. Aktawan and Z. Mufrodi, IOP Conference series : Earth and Environmental Science, vol 245 (2019) p 1

[18] G. H. Soegiantoro, J. Chang, P. Rahmawati, M. F. Christiani, and Z. Mufrodi, Energy Procedia, Vol 158 (2019) p 1105

[19] E. Astuti and Z. Mufrodi, Int. J. of Smart Grid and Clean energy (IJSGCE), vol 8 (2) (2019) p 201

[20] A. Gnanaprakasam, V.M. Sivakumar, A. Surendhar, M. Thirumarimurugan, and T. Kannadasan, Journal of Energy, Vol 213 (2013) p 1-10 
HASIL CEK_The Formation of Local Catalyst From Zeolite, Characterization and Performance in the Reaction

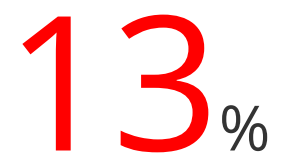

SIMILARITY INDEX

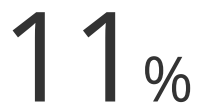

INTERNET SOURCES

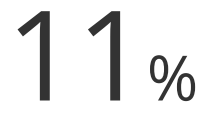

PUBLICATIONS
$7 \%$

STUDENT PAPERS

1 Gianina Martha A. Tajanlangit, Leslie Joy L.

Diaz. "Effect of Processing Parameters on the

Diameter and Morphology of Electrospun

Iron-Modified Montmorillonite (Fe-

MMT)/Polycaprolactone Nanofibers", Key

Engineering Materials, 2020

Publication

2

Vladimir S. Tsepelev, Yuri N. Starodubtsev,

K.M. Wu, Nadezhda P. Tsepeleva.

"Thermomagnetic Analysis of the

Crystallization in Soft Magnetic

Nanocrystalline Alloys", Key Engineering

Materials, 2020

Publication

3 www.hindawi.com

Internet Source

4 Submitted to Universiti Teknologi MARA Student Paper 

for weight gain on pregnancy period",

Nutrition \& Food Science, 2021

Publication

7 Submitted to University of South Florida

Student Paper

8 "Valorisation of Agro-industrial Residues -

Volume II: Non-Biological Approaches",

Springer Science and Business Media LLC,

2020

Publication

9 Submitted to K L University

Student Paper

10 Anti-Corrosion Methods and Materials,

Volume 61, Issue 3 (2014-09-16)

Publication

11 worldwidescience.org

Internet Source

12 secureservercdn.net

Internet Source 